Kennesaw State University

DigitalCommons@Kennesaw State University

Faculty Publications

1987

\title{
Molecular Determinants for Cannabinoid Activity: Refinement of a Molecular Reactivity Template
}

Patricia H. Reggio

Kennesaw State University

Follow this and additional works at: http://digitalcommons.kennesaw.edu/facpubs

Part of the Pharmacology Commons

\section{Recommended Citation}

Reggio PH. 1987. Molecular determinants for cannabinoid activity: Refinement of a molecular reactivity template. NIDA Research Monograph 79:82-95.

This Article is brought to you for free and open access by DigitalCommons@Kennesaw State University. It has been accepted for inclusion in Faculty Publications by an authorized administrator of DigitalCommons@Kennesaw State University. For more information, please contact 


\title{
Molecular Determinants for Cannabinoid Activity: Refinement of a Molecular Reactivity Template
}

\author{
Patricia H. Reggio, Ph.D.
}

\section{INTRODUCTION}

Numerous studies of structure-activity relationships (SARs) in the cannabinoid series have been published; e.g., see review by Sofia (1978) and some more recent work by Martin et al. (1984a, 1984b) and Narimatsu et al. (1985). An observation which emerges from a review of all of these studies is that some cannabinoids can be structurally dissimilar as in delta-9-tetrahydrocannabinol (delta-9-THC) and Abbott 40656 (Rosell et al. 1979) and yet can have similar activities; whereas others, which show only slight structural differences as in 10alpha-OH-delta-8-THC and 10-beta-OH-delta-8-THC (Edery et al. 1971). can exhibit dramatic activity differences (figure 1). This observation emphasizes that a common basis for the activity of these compounds must be sought in more than their mere three-dimensional structures.

Traditionally, cannabinoid SARs have been focused almost entirely on the independent contribution of certain structural groups ("functional groups") of the molecules. These SARs have been compiled into extensive "lists of requirements" (Razdan 1984). Certain regions or conformations of the molecules have been proposed to be important. These regions or conformations include a methyl group in the plane of the aromatic ring, a free phenol, and a free C-4(C-5') aromatic position (Edery et al. 1971); the phenolic hydroxyl group (Uliss et al. 1975); the side chain (Osgood et al. 1978); nonplanarity (Binder et al. 1979); and planarity of the molecule (Burstein et al. 1983). Stereoselectivity in the activity of the tetrahydrocannabinols has been reported (Dewey et al. 1984). This type of approach in SAR studies often assumes the following: that functional groups must react directly with specific sites in the receptor, that modification of one group does not affect the reactivity of another, and that geometric and stereometric factors, such as distance and spatial relationships between functional groups, are all important. Such focus on isolated aspects of the cannabinoids ignores the fact that the molecular properties that are directly responsible for the molecular interactions (that lead to the pharmacological effect) are encoded in the entire molecular structure. To date, no characterization of the entire molecule and correlation of this characterization with activity has been attempted in the cannabinoid field.

The importance of quantum chemical methods in describing the physical and chemical properties of molecules is evident in every facet of modern chemical 

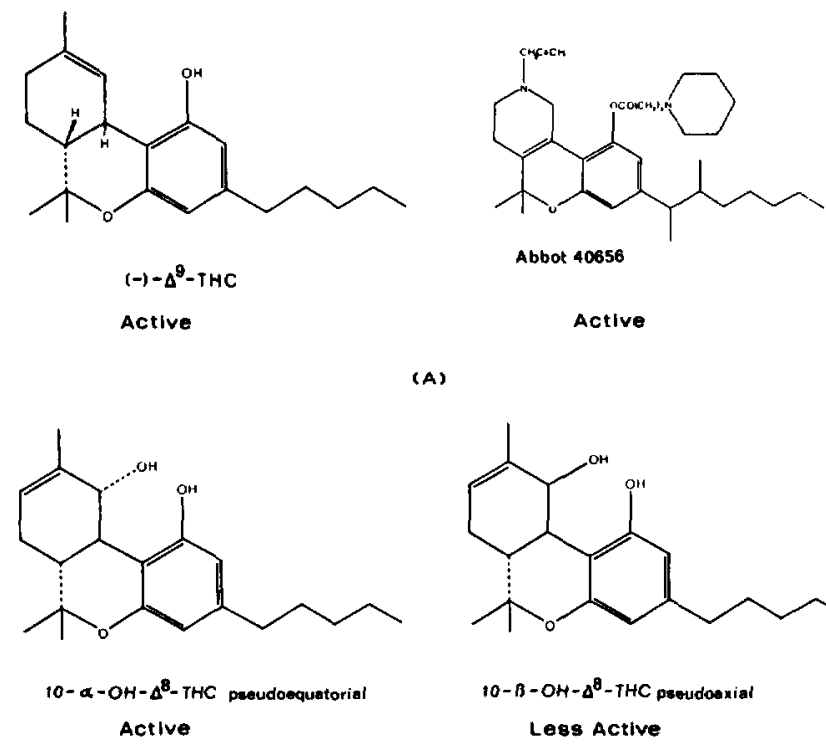

A)

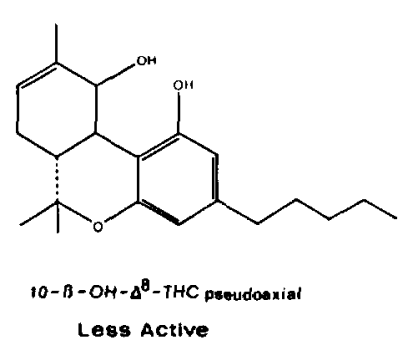

(B)

FIGURE 1. Cannabinoids (a) which are structurally dissimilar yet exhibit similar activities, and (b) which are structurally similar yet exhibit different activities. From Reggio and Mazurek 1987. Copyright 1986 by Elsevier Science Publishers B.V. (Amsterdam).

research and is very well documented. In the study of biological systems, experimental data must be obtained in a variety of forms and from many different sources. The value of quantum chemical approaches to the study of biological systems is in an ability to analyze, interpret, and rationalize all experimental observations on molecular processes in a unified language based on the primary principles of physics. Considerable evidence exists proving the relative success of theoretical approaches. These approaches have elucidated specific mechanisms of drug action, have provided a basis for rational drug design, and have led to conclusions about the nature of drug-receptor interactions (Dearden 1983; Vida and Gordon 1984). We have used theoretical approaches to successfully describe the molecular determinants for binding of methylenedioxytryptamines at SHT/LSD receptors (Reggio et al. 1981) and have also used theoretical approaches to explain the role that tautormerism plays in the activation of the histamine- $\mathrm{H}_{2}$ receptor by 2-methyl and 4-methylhistamine (Reggio and Mazurek 1987). The basic assumption in any of these theoretical studies of drug action is that the interaction between drugs and their biological targets is dependent on the same molecular parameters that determine chemical interactions and reactions. Molecular Reactivity Characteristics (MRCs) such as molecular electrostatic potentials (MEP), polarizabilities, and proton affinities are molecular properties that determine specific chemical reactivity. In theoretical studies of structure-activity relationships, such MRCs are used to establish how the information necessary for receptor recognition and activation is encoded in the molecular structure of the drug. 
Despite the extensive application of theoretical methods in the study of many pharmacological systems, very little attention has been focused on the cannabinoids to date. Those theoretical studies on cannabinoids which have been published have not focused on the calculation of molecular reactivity characteristics. Most of these studies have concentrated on the calculation of conformation in an attempt to predict the most probable geometry (lowest energy conformer) and its relation to activity. The structures and energies of delta-9THC and three other cannabinoids obtained by Westheimer calculations and extended Huckel molecular orbital calculations have been reported (Archer et al. 1970). Theoretical studies of cannabinoids with analgetic and anticonvulsant activity have also been reported (Johnson et al. 1982; Tamir et al. 1980). The work presented here extends beyond the considerations which have prevailed in theoretical studies of the cannabinoids. The aim of this work is to reveal elements of molecular reactivity that are related to psychopharmacological activity.

A major step in identifying the MRCs necessary for cannabinoid activity was to select a template molecule (a molecule with demonstrated activity whose MRCs can be used as a basis for comparison with those of other cannabinoids). Since (-)trans-delta-9-THC (delta-9-THC) has been reported to be the major psychoactive component of cannabis (Gaoni and Mechoulam 1964, 1971) and since studies indicate that it can exert behavioral effects without metabolic activation (Carney et al. 1979), delta-9-THC was chosen as the template molecule for this study. Figure 2 illustrates the numbering systems which are commonly employed in the literature for delta-9-THC.

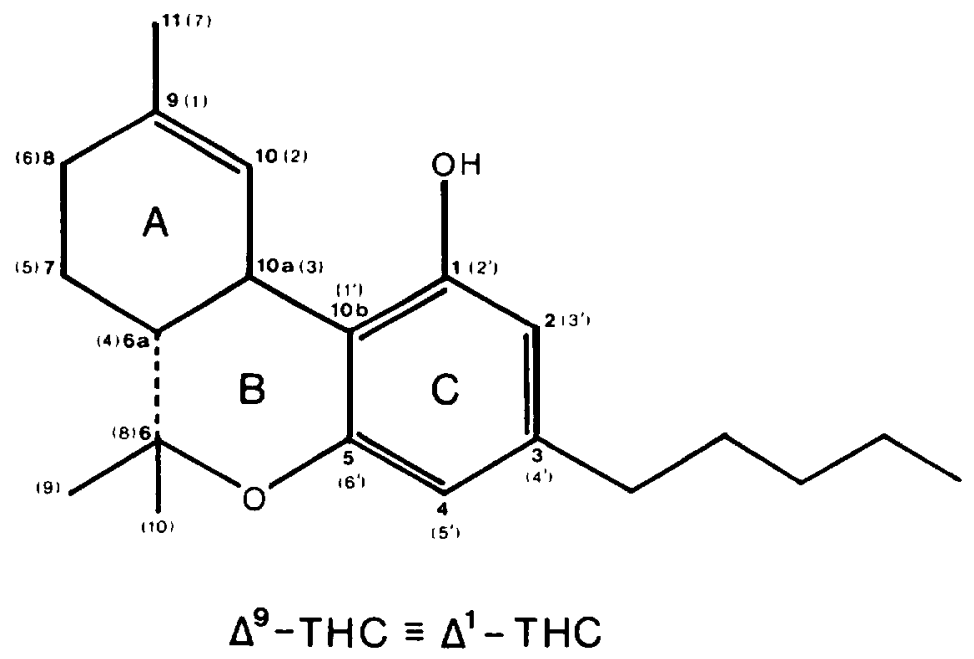

FIGURE 2. An illustration of the two numbering systems which are commonly employed for the cannabinoids. From Reggio and Mazurek 1987. Copyright 1986 by Elsevier Science Publishers B.V. (Amsterdam). 
Our first working hypothesis deals with two components of the delta-9-THC structure which confer reactivating characteristics upon the molecule that are crucial to activity. These components are the lone pairs of electrons of the phenol oxygen (these lone pairs generate reactivity properties dependent on the orientation of the $\mathrm{OH}$ bond relative to the carbocyclic ring, Ring $\mathrm{A}$ ), and the orientation of the carbocyclic ring, Ring A (this ring and its orientation generate hydrophobic properties). The spatial arrangements of these reactivity characteristics are the components of the template to which the characteristics of other cannabinoids can subsequently be compared.

\section{Template for Cannabinoid Activity}

Recently, we reported the characterization of the template molecule delta-9-THC (Reggio and Mazurek, 1987). Since the molecular reactivity characteristics of delta-9-THC are to be used as a basis of comparison with other cannabinoids, the essential features of the template are presented here. The reader should refer to the original paper (Reggio and Mazurek 1987), however, for all calculational details.

The lowest energy conformer of delta-9-THC as obtained by conformational analysis is shown in figure 3. It is clear from this figure that delta-9-THC is a nonplanar molecule. The carbocyclic ring (Ring A) of delta-9-THC exists in a half-chair conformation. Ring $\mathrm{B}$ assumes a conformation such that the axial $\mathrm{C}_{6}$ methyl group is on the same side of the molecule as $\mathrm{H}_{10 \mathrm{a}}$ and is much closer to $\mathrm{H}_{10 \mathrm{a}}$ than is the other methyl group. In this optimized structure, the phenolic hydrogen points away from the carbocyclic ring (dihedral angle, $\mathrm{C}_{2}-\mathrm{C}_{1}-0-\mathrm{H}=-$ $\left.1^{\circ}\right)$. Figure 4 shows a different perspective of the molecule. Here, delta-9-THC is shown in the direction parallel to the vector from $\mathrm{C}_{2}$ to $\mathrm{C}_{10 \mathrm{~b}}$. From this perspective, the conformation of the carbocyclic ring (Ring A) causes the top part of the ring to move to the left, thus permitting no protrusion of Ring A into the bottom face of the molecule. It is part of our working hypothesis that this orientation is necessary for cannabinoid activity. The conformation of the carbocyclic ring may allow for nondirectional hydrophobic interactions.

The lone pairs of electrons of the phenol oxygen generate directional reactivity properties dependent on the orientation of the $\mathrm{OH}$ bond relative to the carbocyclic ring. Studies of molecular energy as a function of rotation about the $\mathrm{C}_{1}-\mathrm{O}$ axis reveal that two minimum energy conformations of the phenolic $\mathrm{OH}$ exist. In Conformation $\mathrm{I}$, the phenolic $\mathrm{OH}$ is slightly bent out of the plane of the aromatic ring with the hydrogen pointing away from Ring $A\left(\mathrm{C}_{2}-\mathrm{C}_{1}-\mathrm{O}-\mathrm{H}\right.$ dihedral angle, $\boldsymbol{\tau}=-1^{\circ}$ ). In Conformation II, the phenolic hydrogen is below the plane of the aromatic ring and is pointing toward Ring $A\left(\boldsymbol{\tau}=155^{\circ}\right)$. The conformation of the rest of the molecule remains essentially unchanged.

The molecular electrostatic potential (MEP) is a molecular reactivity characteristic that determines specific chemical reactivity. It is an important determinant of drug action. The electrostatic potential field extends into space and influences nearby molecules. Unless the fields of a drug and its receptor are complementary, they will not attract or bind to one another. Indeed, electrostatic forces appear to guide an incoming drug into its receptor site and align so that shorter range binding forces can take effect (Tucker 1984). Therefore, a very direct indication of the nature and extent of electrostatic drug-receptor interactions can be obtained by mapping the potential generated by a molecule. 


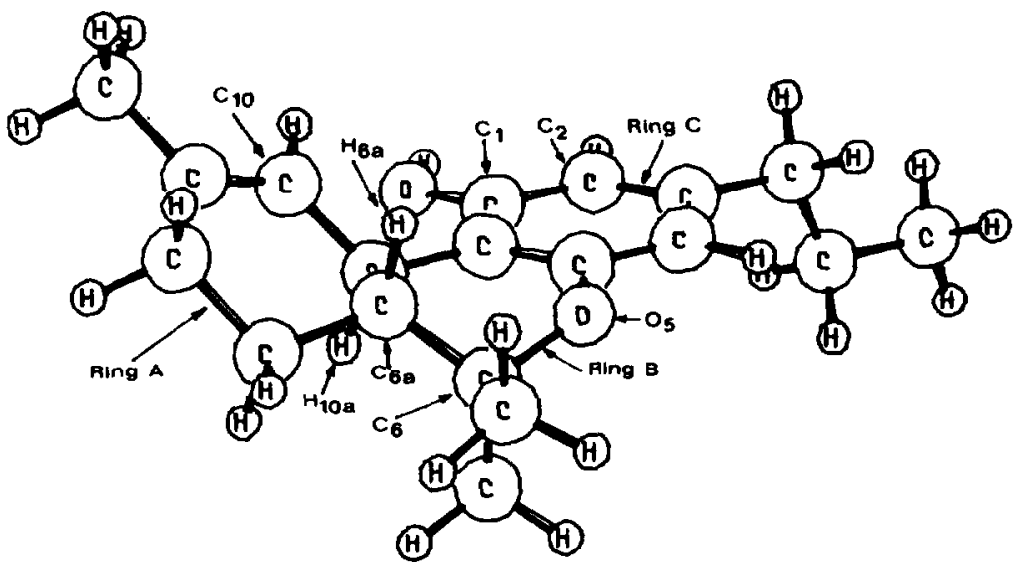

FIGURE 3. Conformation of delta-9-THC (with propyl side chain) as determined by MM2. From Reggio and Mazurek 1987. Copyright 1986 by Elsevier Science Publishers B.V. (Amsterdam).

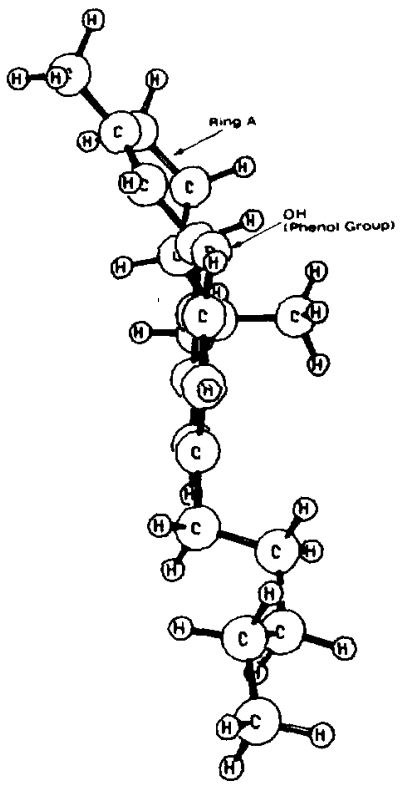

FIGURE 4. Conformation of delta-9-THC as determined by MM2: here the perspective of Ring $A$ is viewed in the direction parallel to the vector from $C_{2}$ to $C_{10 b}$. From Reggio and Mazurek 1987. Copyright 1986 by Elsevier Science Publishers B.V. (Amsterdam). 
The calculated electrostatic potential patterns generated by the bottom face of delta-9-THC in each of its minimum energy conformers are shown in figures 5 and 6 . These patterns are composed of lines of equipotential energy in $\mathrm{kcal} / \mathrm{mole}$ that would be felt by a test positive charge placed at any specified point on the map. Figures 5 and 6 illustrate the regions of negative potential in planes parallel to the benzene ring at distances of 1.5 As below the plane of the ring. Because delta-9-THC is a nonplanar molecule. the MEPs differ depending upon whether the molecule is viewed from above or below. We found that the change in the position of the phenol group from Conformation I to Conformation II caused a distinguishable difference in the MEPs of the two conformers when viewed from the bottom face.

At this stage of the investigation, it was impossible to identify which conformation of the phenolic OH of delta-9-THC (I or II) was more relevant at the site of action. Hence, the MEPs shown in figures 5 and 6 along with the conformation of Ring A, as illustrated in figure 4, formed the preliminary set of molecular reactivity characteristics for cannabinoid activity.

\section{Refinement of the Template}

In order to refine our template, a comparison of the MRCs of delta-9-THC with those of another cannabinoid was undertaken. Edery et al. (1971) reported that in rhesus monkey behavioral tests the replacement of the phenolic hydrogen of delta-9-THC with a methyl group renders the molecule inactive. This inactive cannabinoid, O-methyl-delta-9-THC (figure 7), was selected for comparison in order to assess the importance of the position of the lone pairs of electrons of the phenol oxygen. We report here the results of our comparison of the properties of O-methyl-delta-9-THC with those of the delta-9-THC reactivity template.

\section{METHODS OF PROCEDURE}

\section{Conformational Study of O-Methyl-Delta-9-THC}

The first step in the characterization was the conformational analysis of $\mathrm{O}$ methyl-delta-9-THC. The force field or molecular mechanics method as encoded in the program MM2 (Allinger and Yuh 1980) was used in this analysis. The force field available in MM2 has been parameterized for oxygen containing molecules and has proven satisfactory for the calculation of structures and energies of oxygen containing compounds (Allinger et al. 1980). The X-ray structure of delta-9-THC Acid B (Rosenquist and Ottersen 1975) was used to obtain an input geometry (i.e., bond lengths, bond angles, and dihedral angles for the fused ring skeleton of delta-9-THC). Necessary atoms were added to this skeleton at standard bond lengths and bond angles (Mitchell and Cross 1965) to produce an input geometry for O-methyl-delta-9-THC in the MM2 calculation. In the calculational scheme for the template molecule, delta-9-THC, molecular size constraints necessitated reducing the pentyl side chain to propyl (Reggio and Mazurek 1987). In order to maintain consistency, the side chain in O-methyldelta-9-THC was also reduced to propyl. Such a modification was acceptable since the focus of this study is on the fused ring structure and the phenol group and not on the side chain.

Because the position of the methoxy group was very important to our working hypothesis, two studies of the molecular energy as a function of rotation about the $\mathrm{C}_{1}-\mathrm{O}$ axis were conducted. In the first study, the dihedral driver option in 


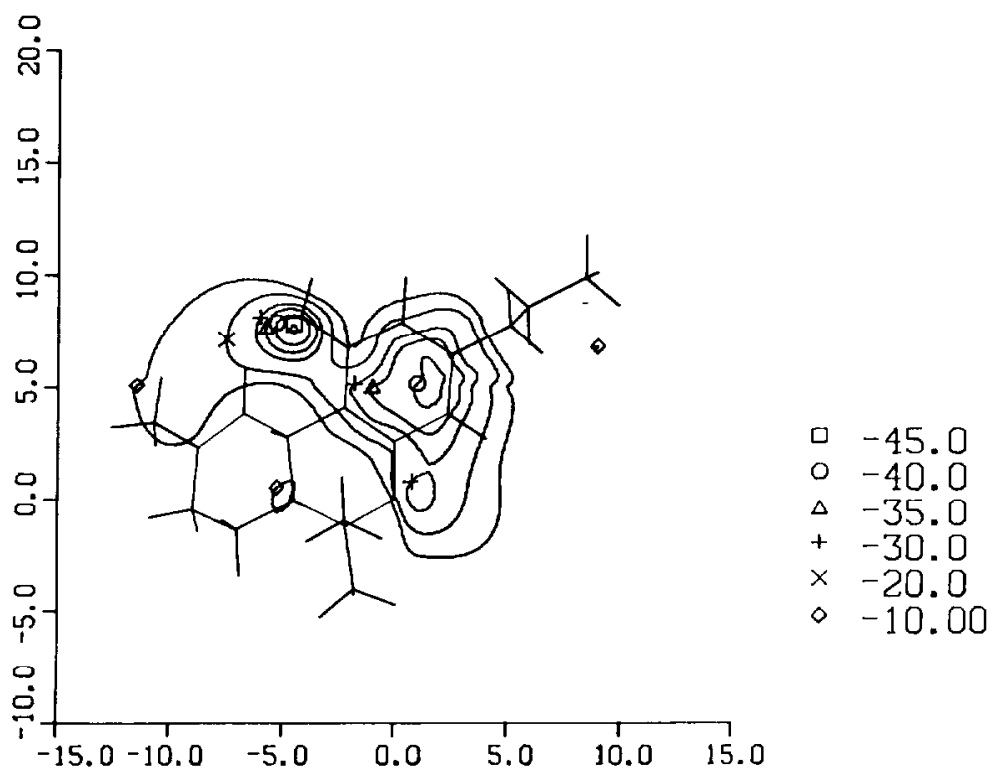

FIGURE 5. Molecular electrostatic potential of the bottom face of delta-9-THC (Conformational I). Contours represent the MEP in a plane $1.5 \AA$ below the aromatic ring. Values are in Kcal/mole. From Reggio and Mazurek 1987. Copyright 1986 by Elsevier Science Publishers B.V. (Amsterdam).

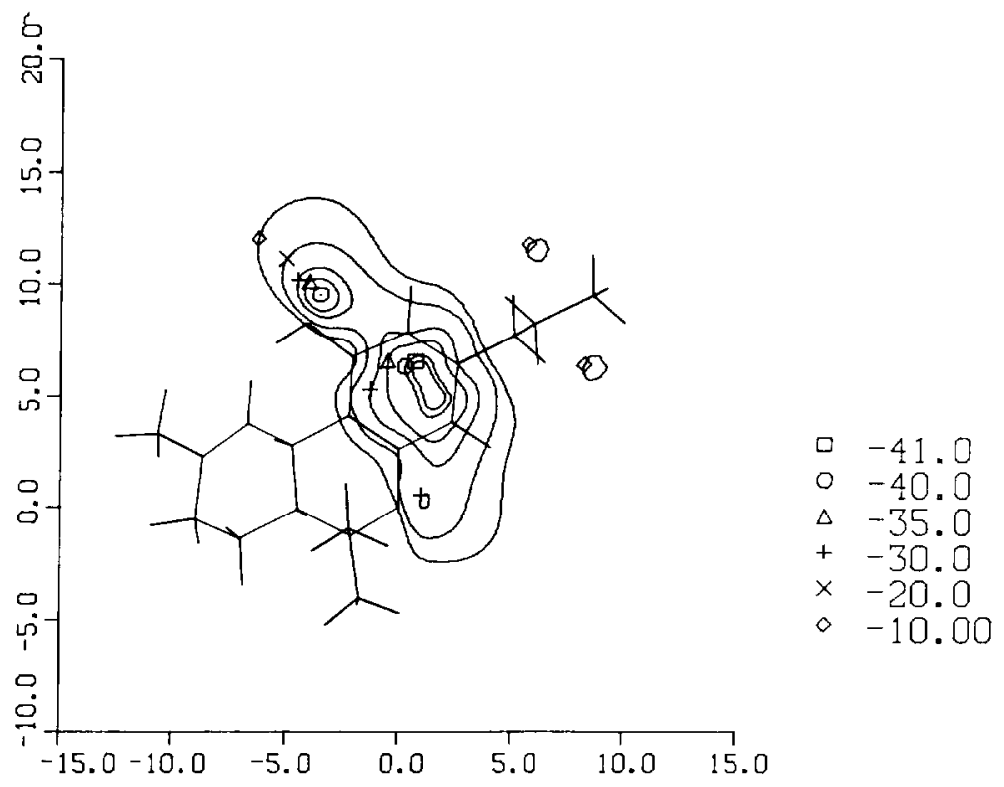

FIGURE 6. Molecular electrostatic potential of the bottom face of delta-9-THC (Conformational II). See figure 5 for details. From Reggio and Mazurek 1987. Copyright 1986 by Elsevier Science Publishers B.V. (Amsterdam). 


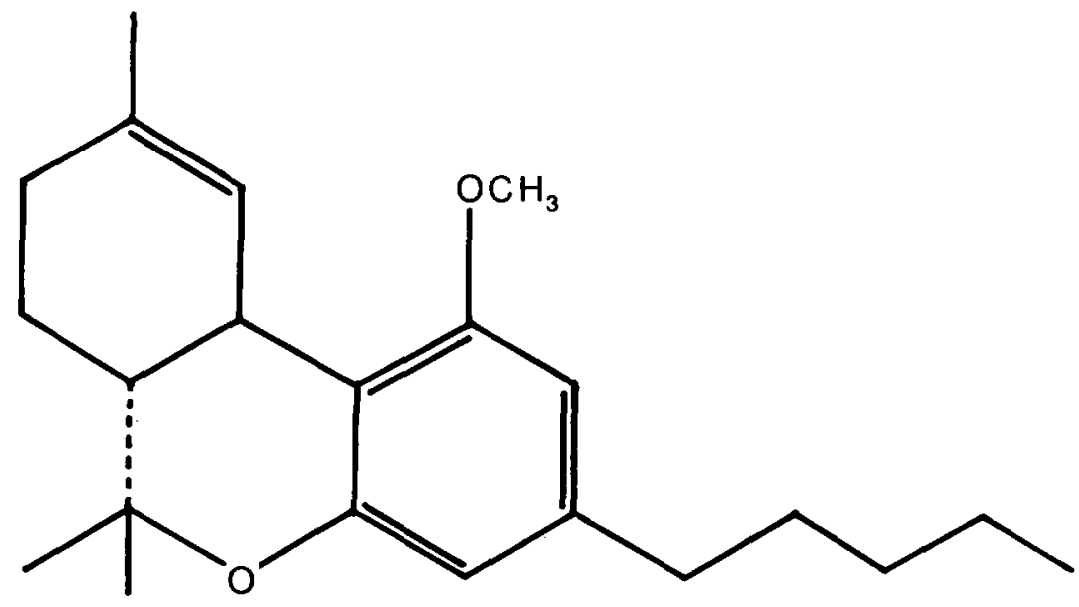

FIGURE 7. O-methyl-delta-9-THC

the MM2 program (Allinger and Yuh 1980) was used. Rotations in 36 steps were made about the $\mathrm{C}_{1}-\mathrm{O}$ axis.

In the second study, an SCF calculation was performed for a model fragment of O-methyl-delta-9-THC (see figure 8). The Gaussian 80 system of programs and the STO-3G basis set were employed here (Fluder et al. 1980). Initially, all atoms in the fragment were frozen in their optimized positions. These positions were determined by MM2 calculations for the full molecule. Rotations of the methoxy group in 18 steps were made about the $\mathrm{C}_{1}-\mathrm{O}$ axis.

\section{RESULTS AND DISCUSSION}

\section{Conformational Analysis}

Figure 9 shows the minimum energy conformer of O-methyl-delta-9-THC as obtained from the MM2 calculation. Previous studies have predicted that the cyclohexene ring (Ring A) of delta-9-THC should exist predominantly in a halfchair-like conformation (Archer et al. 1970). The present calculations indicate that Rng A retains this conformation in O-methyl-delta-9-THC. As a result of the interaction between the $\mathrm{C}_{6}$ methyl groups and $\mathrm{H}_{6 \mathrm{a}}$, Ring $\mathrm{B}$ assumes a conformation such that the axial $\mathrm{C}_{6}$ methyl group is on the same side of the molecule as $\mathrm{H}_{10 \mathrm{a}}$ and is much closer to $\mathrm{H}_{10 \mathrm{a}}$ than is the other methyl group. The substituents on $\mathrm{C}_{6}$ and $\mathrm{C}_{6 \mathrm{a}}$ are staggered with respect to one another (optimized $\mathrm{C}_{10 \mathrm{a}}-\mathrm{C}_{6 \mathrm{a}}-\mathrm{C}_{6}-\mathrm{O}_{5}$ dihedral angle is $\left.63^{\circ}\right)$. Here, the numbering system employed is the same as that for delta-9-THC (see figure 2).

The $\mathrm{C}_{1}$ methoxy group is subject to steric interaction with the $\mathrm{C}_{10}$ proton. This interaction causes the methoxy oxygen to bend slightly out of the plane of the benzene ring. The methoxy group optimizes at a position away from Ring $\mathrm{A}$ (optimized $\mathrm{C}_{2}-\mathrm{C}_{1}-\mathrm{O}-\mathrm{C}$ dihedral angle is $-5^{\circ}$ ). 


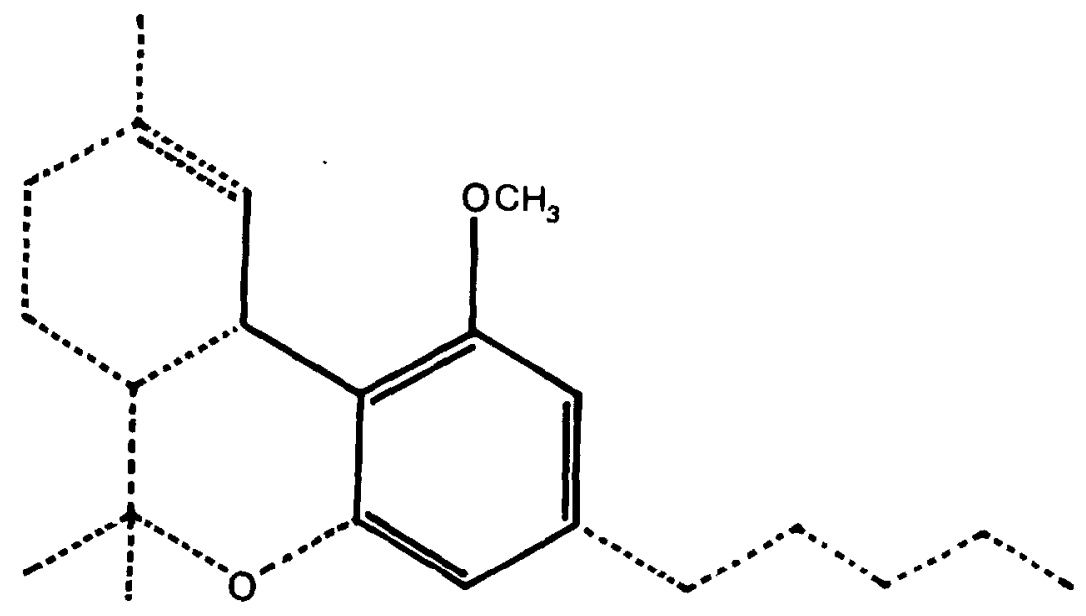

FIGURE 8. Model fragment for O-methyl-delta-9-THC.

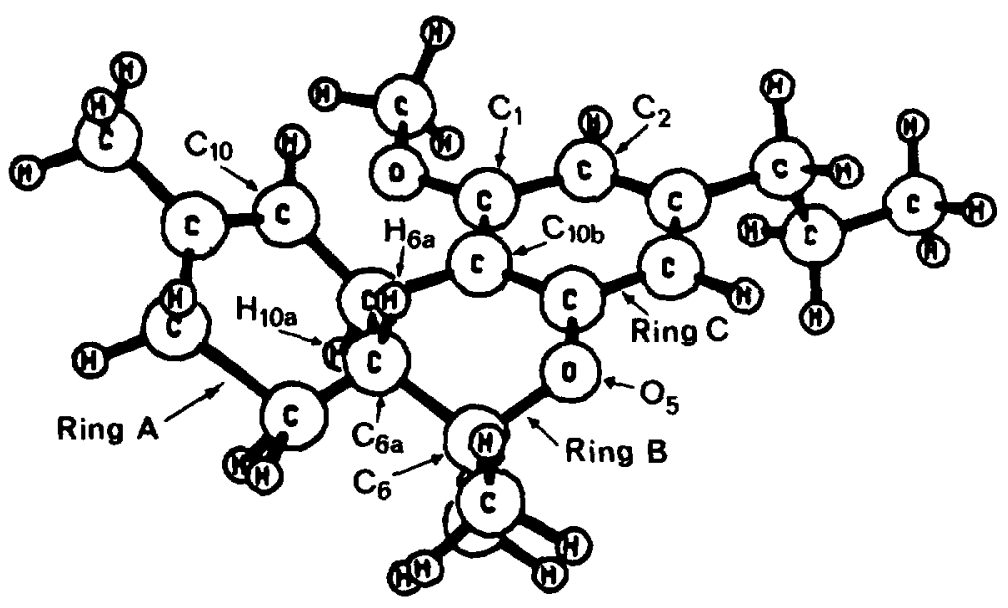

FIGURE 9. Conformation of O-methyl-delta-9-THC (with propyl side chain) as determined by MM2. 
Optimized bond lengths are within $.01 \AA$ of the following values: $\mathrm{C}_{\mathrm{sp}}$ P2- $\mathrm{C}_{\mathrm{sp}} 2$ $1.40 \AA, \mathrm{C}_{\mathrm{sp}} 2-\mathrm{C}_{\mathrm{sp}} 31.51 \AA, \mathrm{C}_{\mathrm{sp}} 3-\mathrm{C}_{\mathrm{sp}} 31.54 \AA, \mathrm{C}_{\mathrm{sp}} 2-\mathrm{O} 1.37 \AA, \mathrm{C}_{\mathrm{sp}} 3-\mathrm{O}$ $1.41 \AA, \mathrm{C}_{\mathrm{sp}} 2-\mathrm{H} 1.10 \AA$, and $\mathrm{C}_{\mathrm{sp}} 3-\mathrm{H} 1.11 \AA$.

Figure 10 shows a perspective of the molecule viewed in the direction parallel to the vector from $\mathrm{C}_{2}$ to $\mathrm{C}_{10 \mathrm{~b}}$ From this perspective, the conformation of Ring $\mathrm{A}$ causes the top part of the ring to move to the left, thus permitting no protrusion of Ring A into the bottom face of the molecule. A comparison of figure 10 with figure 4 reveals that the position of Ring A in O-methyl-delta-9-THC mimics that of Ring $\mathrm{A}$ in delta-9-THC.

The results of the MM2 study of molecular energy as a function of rotation about the $\mathrm{C}_{1}-\mathrm{O}$ axis are summarized in figure 11 . There are local minima at $\boldsymbol{\tau}=$ $-50^{\circ}$ and $85^{\circ}$ separated by a $0.8 \mathrm{kcal}$ barrier. The SCF results for the model fragment of O-methyl-delta-9-THC agreed very well with those above. The SCF method pinpointed two minimum energy conformers $\boldsymbol{\tau}=-5^{\circ}$ and $\boldsymbol{\tau}=85^{\circ}$ separated by a $1.0 \mathrm{kcal}$ barrier.

It is clear from figure 11 that a $\boldsymbol{\tau}$ of $155^{\circ}$ (which corresponds to Conformation II of delta-9-THC) does not represent an energy minimum for the molecule. In fact, in the MM2 study, the conformation with $\boldsymbol{\tau}=155^{\circ}$ is $7.3 \mathrm{kcal}$ higher in energy than the minimum energy conformer of O-methyl-delta-9-THC.

In its minimum energy conformation, the methoxy group of O-methyl-delta-9THC essentially adopts Conformation I of the template. In this conformation, the lone pairs of electrons of the phenol oxygen are directed toward Ring A. However, the methoxy group cannot mimic Conformation II of the template in which the lone pairs of electrons of the phenol oxygen are directed away from Ring A. On the basis of these results, the inactivity of O-methyl-delta-9-THC can be explained by the fact that the molecule cannot mimic Conformation II of delta-9-THC. These results seem to indicate, then, that it is Conformation II which is the more relevant conformation at the site of action.

In an early SAR study, Edery et al. (1971) postulated the need for a free phenol for cannabinoid activity. Recently, Binder and Franke (1982) have proposed a picture of delta-9-THC interacting with its hypothetical receptor. In this picture, the phenolic hydrogen is shown to form a hydrogen bond with the receptor. Such a hypothetical drawing implies the necessity of a phenolic hydrogen for activity. It is possible to argue from this viewpoint that O-methyldelta-9-THC is inactive due to its lack of a phenolic hydrogen. Although the demonstrated activity of some esterified THC would argue against the necessity of a phenolic hydrogen for activity, there appears to be no definitive compound yet synthesized which can answer this question. In the next stage of our investigation, we hope to propose new cannabinoids which could be useful in delineating an answer.

\section{CONCLUSIONS}

The finding that O-methyl-delta-9-THC cannot mimic Conformation II of delta9-THC in which the lone pairs of electrons of the phenol oxygen are directed away from Ring A has led to a refinement of our template for cannabinoid activity. This inability of O-methyl-delta-9-THC to mimic Conformation II may cause the inactivity of the molecule. As a result of this finding, we have tentatively refined our template for cannabinoid activity to include two aspects. 


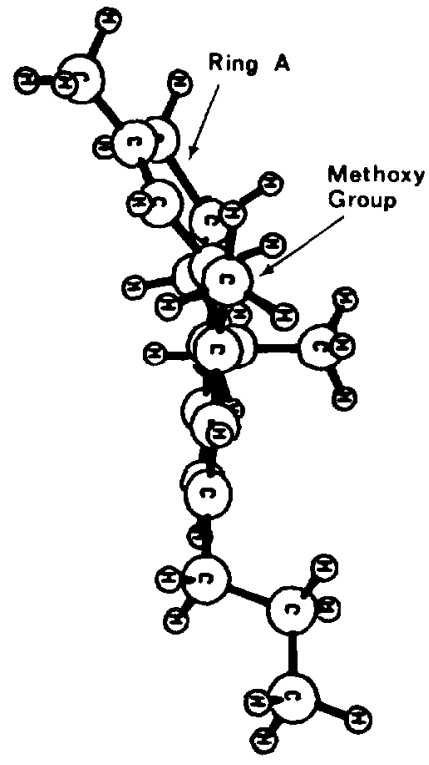

FIGURE 10. Conformation of O-methyl-delta-9-THC (with propyl side chain) as determined by MM2.

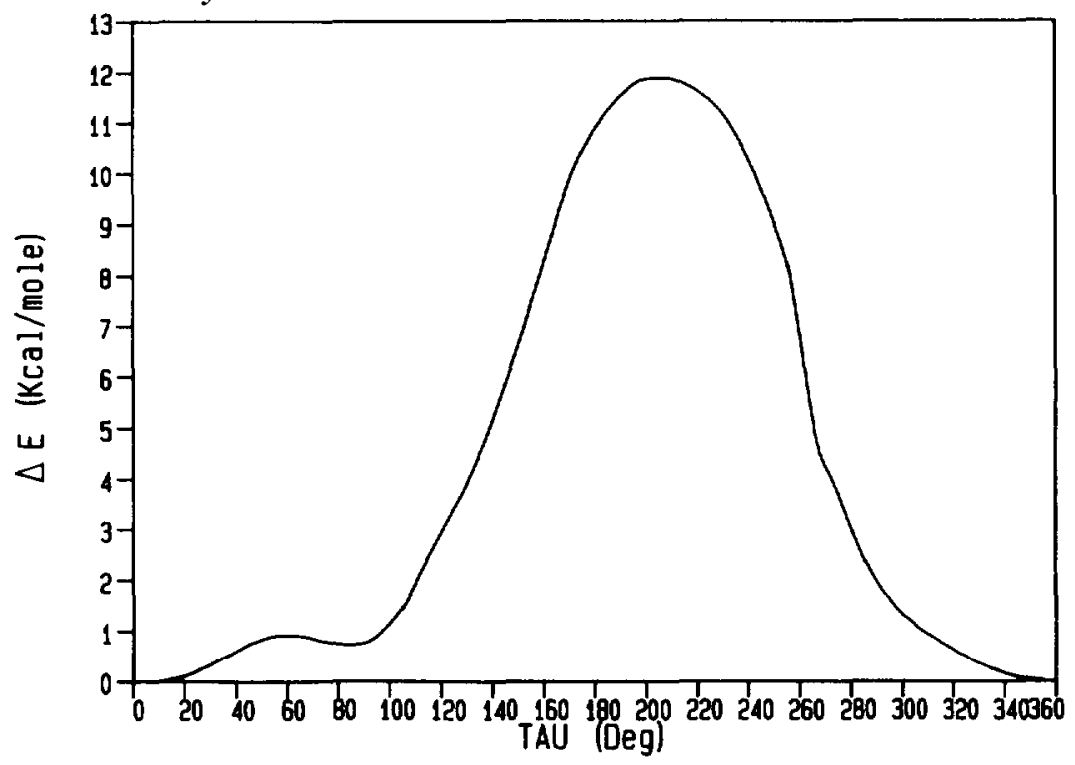

FIGURE 11. Conformation of O-methyl-delta-9-THC as determined by MM2: here the perspective of Ring $A$ is viewed in the direction parallel to the vector from $C_{2}$ to $C_{10 \mathrm{~b}}$. 
1. The first aspect is the orientation of the lone pairs of electrons of the phenol oxygen such that these lone pairs point away from Ring A (Conformation II) (these lone pairs generate directional reactivity properties).

2. The second aspect is the orientation of Ring A such that the ring moves out of the bottom face of the molecule (this conformation is likely to allow for nondirectional hydrophobic interactions).

Further refinements of this template will be made in subsequent comparisons of the template MRCs with those of other cannabinoids.

\section{REFERENCES}

Allinger, N.L., and Yuh, Y.H. MM2. Ouantum Chemistry Program Exchange 13:395, 1980.

Allinger, N.L.; Chang, S.-H.; Glaser, D.H.; and Honig, H. An improved molecular mechanics force field for alcohols, and ethers. Isr $\underline{\mathrm{J}} \underline{\mathrm{Chem}}$ 20:5156, 1980.

Archer, R.A.; Boyd, D.B.; Demarco, P.V.; Tyminski, I.J.; and Allinger, N.L. Structural studies of cannabinoids. A theoretical and proton magnetic resonance analysis. J Am Chem Soc 92(17):5200-5206, 1970.

Binder, M., and Franke, I. Is there a THC-receptor? In: Hucho, F., ed. Neuroreceotors. Berlin and New York: Walter de Gruyter, 1982. pp. 151161.

Binder, M.; Edery, H.; and Porath, G. Delta-7-tetrahydrocannabinol, a nonpsychotropic cannabinoid: Structure-activity considerations in the cannabinoid series. In: Nahas, G.G., and Paton, W.D.M., eds. Marihuana Biological Effects: Analysis, Metabolism, Cellular Responses, Reproduction, and Brain. Oxford: Pergammon Press, 1979. pp. 71-80.

Burstein, S.; Hunter, S.A.; and Ozman, K. XII. The effect of cannabinoid structure on the synthesis of prostaglandins by human lung fibroblasts. Mol Pharm 23:121-126, 1983.

Carney, J.M.; Balster, R.C.; Martin, B.R.; and Harris, L.S. Effects of systemic and intraventricular administration of cannabinoids on schedule-controlled responding in the squirrel monkey. J Pharmacol Exp Ther 210:399-404, 1979.

Dearden, J.C., ed. Ouantitative Approaches to Drug Design. Amsterdam: Elsevier, 1983. 296 pp.

Dewey, W.; Martin, B.; and May, E. Cannabinoid stereoisomers: Pharmacological effects. In: Smith, D.E., ed. CRC Handbook of Stereoisomers: Drugs in Psychopharmacology. Boca Raton: CRC Press, 1984. pp. 317-321.

Edery, H.; Grunfeld, Y.; Ben-Zvi, Z.; and Mechoulam, R. Structural requirements for cannabinoid activity. Ann NY Acad Sci 191:40-53, 1971

Fluder, E.J.; Schlegel, H.B.; and Topiol, S.W. Gaussian 80 (IBM Version), unpublished, 1980.

Gaoni, Y., and Mechoulam, R. Isolation, structure, and partial synthesis of an active constituent of hashish. J Am Chem Soc 86:1646-1647, 1964.

Gaoni, Y., and Mechoulam, R. The isolation and structure of delta-1tetrahydrocannabinol and other neutral cannabinoids from hashish. $\underline{\mathrm{J}} \underline{\text { Am }}$ Chem Soc 93:217-224, 1971.

Johnson, M.R.; Melvin, L.S.; and Milme, G.M. Prototype cannabinoid analgetics, prostaglandins and opiates - a search for points of mechanistic interaction. Life Sci 31:1703-1706, 1982. 
Martin, B.R.; Harris, L.S.; and Dewey, W.L. Pharmacological activity of delta-gTHC metabolites and analogs of CBD, delta-8-THC and delta-9-THC. In: Agurell, S.; Dewey, W.L.; and Willette, R.E., eds. The Cannabinoids; Chemical, Pharmacologic, and Therapeutic Aspects. New York: Academic Press, 1984a. pp. 523-544.

Martin, B.R.; Kallman, M.J.; Kaempf, G.F.; Harris, L.S.; and Dewey, W.L. Pharmacological potency of R- and S-3'-hydroxy-delta-9-

tetrahydrocannabinok Additional structural requirement for cannabinoid activity. Pharmacol Biochem Behav 21:61-65, 1984b.

Mitchell, A.D., and Cross, L.C., eds. Tables of Interatomic Distances and Configurations in Molecules and Ions, Special Publication No. 11, 1958; Special Publication No. 18, 1965.

Narimatsu, S.; Matsubara, K.; Shimoniski, T.; Watanabe, K.; Yamamoto, I.; and Yoshimura, H. Pharmacological activities in the mouse of delta-9tetrahydrocannabinol metabolites oxidized at the 8-position. Chem Pharm Bull 33(1):392-395, 1985.

Osgood, P.R.; Howes, J.F.; Razdan, R.K.; and Pars, H.G. Drugs derived from cannabinoids. 7. Tachycardia and analgesia structure-activity relationships in delta-9-tetrahydrocannabinol and some synthetic analogues. $\underline{\mathrm{J}} \underline{\mathrm{Med}} \underline{\mathrm{Chem}}$ 2(8):809-811, 1978.

Razdan, R.K. Chemistry and structure-activity relationships of cannabinoids: An overview. In: Agurell, S.; Dewey, W.L.; and Willette, R.E., eds. The Cannabinoids: Chemical, Pharmacologic, and Therapeutic Aspects. New York: Academic Press, 1984.

Reggio, P.H. and Mazurek, A.P. A molecular reactivity template for cannabinoid activity. J Mol Struc (Theochem) 149:331-343, 1987.

Reggio, P.; Weinstein, H.; Osman, R.; and Topiol, S. Molecular determinants for binding of methylenedioxytryptamines at 5HT/LSD receptors. Int $\underline{\mathrm{J}}$ Quantum Chem QBS8:373-384, 1981.

Reggio, P.; Topiol, S.; and Weinstein, H. Molecular determinants for the agonist activity of 2-methylhistamine and 4-methylhistamine at H2-receptors. I Med Chem 29:2412-2415, 1986.

Rosell, S.; Bjorkroth, V.; Agurell, S.; Leander, K.; Ohlsson, A.; Martin, B.; and Mechoulam, R. Relation between effects of cannabinoid derivatives on the twitch response of the isolated guinea pig ileum and their psychotropic properties. In: Nahas, G.G., and Paton, W.D.M., eds. Marihuana Biological Effects: Analysis, Metabolism, Cellular Responses, Reproduction, and Brain. Oxford: Pergammon Press, 1979. pp. 63-70.

Rosenquist, E., and Ottersen, T. The crystal and molecular structure of delta-9tetrahydrocannabinolic acid B. Acta Chem Scand 1329:379-384, 1975.

Sofia, R.D. Cannabis: Structure-activity relationships. In: Iverson, L.L.; Iverson, S.D.; and Snyder, S.H., eds. Handbook of Psychopharmacology. Vol . 12. Drugs of Abuse. New York: Plenum Press, 1978. pp. 319-371.

Tamir, I.; Mechoulam, R.; and Meyer, A. Cannabidiol and phenytoin: A structural comparison. J Med Chem 23:220-223, 1980.

Tucker, J.B. Designing molecules by computer. High Technology JAN:52-59, 1984.

Uliss, D.B.; Calzell, H.D.; Handrick, G.R.; Howes, J.F.; and Razdan, R.K. Hashish. Importance of the phenolic hydroxyl group in tetrahydrocannabinols. J Med Chem 18:213-215, 1975.

Vida, J.A., and Gordon, M. Conformationally Directed Drug Design. American Chemical Society Symposium Series 251. Washington: American Chemical Society, 1984. $271 \mathrm{pp}$. 


\section{ACKNOWLEDGMENTS}

Dr. Harel Weinstein consulted on this project. This work was supported in part by grant DA-03934 from the National Institute on Drug Abuse and by a grant of computer time from from the University Computing Center of the City University of New York. Data analysis was done on the PROPHET computer system, a national computational resource sponsored by the NIH through the Division of Research Resources.
AUTHOR
Patricia H. Reggio, Ph.D.
Department of Chemistry
Kennesaw College
Marietta, Georgia 30061 